\title{
COMPORTAMENTO DE GENÓTIPOS DE FEIJOEIRO EM LATOSSOLO VERMELHO DISTROFÉRRICO TÍPICO COM DIFERENTES GRAUS DE COMPACTAÇÃO ${ }^{1}$
}

\author{
VANDEIR GREGÓRIO ALVES ${ }^{2}$ \\ MESSIAS JOSÉ BASTOS DE ANDRADE ${ }^{3}$ \\ JOÃO BATISTA DONIZETI CORRÊA ${ }^{4}$ \\ AUGUSTO RAMALHO DE MORAES ${ }^{5}$ \\ MARCELO VIEIRA DA SILVA ${ }^{2}$
}

\begin{abstract}
RESUMO - Visando a avaliar o comportamento de quatro genótipos de feijoeiro em diferentes condições de compactação do solo, foram conduzidos dois experimentos em campo nas safras das águas 98/99 e seca/99, em um Latossolo Vermelho distroférrico típico da área experimental do Departamento de Agricultura da UFLA. O delineamento experimental utilizado foi em blocos casualizados com quatro repetições e esquema fatorial $6 \times 4$ envolvendo seis níveis de densidade do solo $\left(1,08 ; 1,24 ; 1,36 ; 1,39 ; 1,41\right.$ e 1,50 g.cm $\left.{ }^{-3}\right)$ e quatro genótipos de feijoeiro (cultivares Carioca e Pérola e linhagens ESAL 550 e CI-128). Adotaram-se espaçamento de 0,50 $\mathrm{m}$ entre fileiras, 16 sementes por metro
\end{abstract}

TERMOS PARA INDEXAÇÃO: Compactação do solo, Phaseolus vulgaris L, cultivares e linhagens.

\section{BEHAVIOR OF FOUR COMMON BEAN GENOTYPES IN A OXISOL SUBMITTED TO DIFFERENT COMPACTION DEGREES}

\begin{abstract}
Aiming to compare the behavior of four common bean genotypes at different soil compaction conditions, two field experiments were carried in the spring-summer 98/99, summer - fall/98 sowing seasons, in an Oxisol of the experimental area of UFLA Department of Agriculture. The experimental design was randomized blocks with four replications and 6 x 4 factorial scheme, involving six levels of soil density $\left(1.08 ; 1.24 ; 1.36 ; 1.39 ; 1.41\right.$ and $1.50{\mathrm{~g} . \mathrm{cm}^{-3}}^{-3}$ and four bean genotypes (Carioca and Pérola cultivars and ESAL 550 and CI-128 lineages). It was adopted the spacing of $0.50 \mathrm{~m}$ among rows, with 16 seeds per meter. For soil
\end{abstract}

fertilization, a 4-14-8 formulation was applied at 500 $\mathrm{Kg} \mathrm{ha}^{-1}$ before sowing, and $30 \mathrm{~kg} \cdot \mathrm{ha}^{-1}$ of $\mathrm{N}$, as ammonium sulfate, was applied 25 days after emergency. The initial and final stands, the grain yield and its components (pods number per plant, grains number per pod and one hundred grains mass) were evaluated. The increasing soil compaction degrees reduced the number of plants and the grain yield according to a linear model, independently of seasons and genotypes. The CI-128 lineage was the most productive genotype in the summer-fall season and was a good genotype in the spring-summer sowing season.

e adubação equivalente a $500 \mathrm{~kg} \cdot \mathrm{ha}^{-1}$ de $4-14-8$, sendo a cobertura nitrogenada realizada aos 25 dias após a eamônio. Avaliram-se os estandes inicial e final, o rendimento de grãos e seus componentes (número de vagens grãos) $\mathrm{O}$ aumento do grau de compactação do solo reduziu linearmente o número de plantas, independente de genótipos. O efeito dos graus crescentes de commais consiste independente de linhagem CI-128 foi a mais produtiva na safra da seca e situou-se entre as melhores na safra das águas.

INDEX TERMS: Soil compaction, Phaseolus vulgaris L., cultivars and lineages.

1. Projeto financiado pela FAPEMIG.

2. Mestrando em agronomia/fitotecnia, UNIVERSIDADE FEDERAL DE LAVRAS/UFLA. Caixa Postal 37, 37200-000 - Lavras, MG.

3. Engenheiro Agrônomo, DSc., Professor do Departamento de Agricultura da UFLA, bolsista do CNPq.

4. Engenheiro Agrônomo, DSc., Professor do Departamento de Agricultura da UFLA.

5. Engenheiro Agrônomo, DSc., Professor do Departamento de Ciências Exatas da UFLA. 


\section{INTRODUÇÃO}

A compactação do solo geralmente está relacionada a menor aeração, fluxo de água e resistência à penetração das raízes, e a causa é normalmente atribuída ao intenso tráfego de máquinas e implementos necessários no sistema de plantio.

Lindemann et al. (1982) afirmaram que em razão da aplicação de cargas ou pressões, a compactação provoca um aumento da densidade do solo, pela redução da porosidade e modificação da sua estrutura. Para cada classe de solo, à uma determinada pressão, o grau de compactação dependeria, principalmente, do teor de água (Soane, 1970). No entanto, o conteúdo de argila e o teor de matéria orgânica são constituintes que também influem na suscetibilidade à compactação de um solo (Camargo \& Alleoni, 1997).

Freqüentemente são utilizados, em condições de campo, valores de infiltração para caracterizar o estado de compactação dos solos. Moura Filho \& Buol (1972) compararam os efeitos de 15 anos de cultivos anuais em um Latossolo Roxo e observaram que as taxas de infiltração diminuíram de 82 para $12 \mathrm{~cm} \cdot \mathrm{h}^{-1}$ com a prática do cultivo intensivo. A diminuição da infiltração estava associada a uma grande redução dos macroporos, tanto no horizonte ' $\mathrm{A}$ ' como no ' $\mathrm{B}$ '. A compactação produzida por máquinas pesadas foi considerada a principal causa da diminuição da macroporosidade.

Segundo Andrade (1998), solos argilosos apresentam a desvantagem de dificultar a emergência do feijoeiro, reduzindo a população de plantas. Cita ainda que esses solos apresentam, com maior frequiência, problemas ocasionados por fungos de solo.

As raízes, quando impedidas de penetrar em solos com alta resistência mecânica, desviam-se e tendem a crescer horizontalmente sobre a camada compactada. Isso impede a absorção das reservas de água do subsolo e aumenta a sensibilidade a curtos períodos de seca (Dexter, 1986). Analisando, em duas classes de solo, os fatores que influenciam a resistência do solo à penetração mecânica, Gerard et al. (1982) observaram influência do espaço poroso, densidade do solo, conteúdo volumétrico de água e de argila.

A infiltração de água em Latossolos, em condições normais, é elevada. Essa infiltração, entretanto, pode ser altamente reduzida quando ocorrem camadas compactadas. Precipitações de alta intensidade, o que é uma característica de regiões de cerrado, levam ao escorrimento superficial das águas, acarretando severos efeitos erosivos e diminuindo a quantidade de água in- filtrada nas camadas subsuperficiais do solo (Caudle, 1991).

Trabalhando com camadas compactadas em diferentes profundidades, Lowry et al. (1970) evidenciaram que o seu efeito no rendimento do algodoeiro é mais negativo a $0,10 \mathrm{~m}$ do que a 0,20 ou $0,30 \mathrm{~m}$ de profundidade. Como o sistema radicular efetivo na absorção de nutrientes e água localiza-se na camada mais superficial do perfil, essa poderia ser a provável causa do maior dano da compactação nessa camada superficial.

Primavesi (1983) observou aumento da produtividade na cultura do feijão em compactações num Latossolo Roxo, cujos os valores de macroporosidade atingiram até cerca de $11 \%$, verificando reduções de produtividade com acréscimos posteriores da compactação. Alvarenga (1993) compactou um Latossolo Vermelho Amarelo até a densidade de $1,4 \mathrm{~g} . \mathrm{cm}^{-3}$, reduzindo a macroporosidade de 31 para $10 \%$; isso provocou alterações em alguns processos dinâmicos, como, por exemplo, nas relações água-ar do solo.

Densidade do solo de 1,35 g.cm em Latossolo Vermelho Escuro de textura muito argilosa resultou em ausência de raízes de soja (Borges et al., 1988). Para a mesma cultura, em Terra Roxa Estruturada e Latossolo Roxo de composição granulométrica semelhantes, Moraes (1988) encontrou valores limites de 1,23 e 1,30 g.cm ${ }^{-3}$, respectivamente. Corrêa et al. (1999) observaram que o aumento do grau de compactação, em três classes de solo, reduziu o rendimento de massa seca das raízes e parte aérea de duas variedades de cana-deaçúcar e que densidades acima de 1,$59 ; 1,40$ e 1,46 g. $\mathrm{cm}^{-3}$, respectivamente para Latossolo Vermelho Amarelo textura média, Latossolo Roxo e Latossolo Vermelho Amarelo argiloso, limitaram a penetração de raízes.

Pizaia (1996) observou diferença no desenvolvimento de cultivares de milho em solo compactado, evidenciando existir maior ou menor tolerância à compactação dentro da mesma espécie. Corrêa et al. (1999) também observaram em solos compactados maior crescimento de raízes da variedade de cana de açúcar SP701143 em relação à RB72-454.

Com o presente trabalho objetivou-se estudar, em condições de campo, o comportamento de quatro genótipos de feijoeiro submetidos a diferentes graus de compactação do solo Latossolo Vermelho distroférrico típico.

\section{MATERIAL E MÉTODOS}

O trabalho constou de dois experimentos conduzidos em campo em um Latossolo Vermelho distroférrico típico (Tabela 1) da área experimental do Departamento de Agricultura (DAG) da Universidade Federal 
de Lavras. O primeiro foi conduzido no período de 9/11/1998 a 27/01/1999 e o segundo, de 16/03/1999 a $03 / 06 / 1999$.

Utilizou-se o delineamento experimental em blocos casualizados em 4 repetições e esquema fatorial $6 \mathrm{x}$ 4 envolvendo 6 densidades do solo $(1,08 ; 1,24 ; 1,36$; 1,39; 1,41 e 1,50 g.cm ${ }^{-3}$ ) e 4 genótipos de feijoeiro (cvs. Carioca e Pérola e as linhagens ESAL 550 e CI-128).

Os graus de compactação do solo foram obtidos artificialmente, mediante tráfego de um rolo compactador de 8 toneladas sobre a área experimental previamente irrigada, após subsolagem, aração e gradagem, com diferente número de operações. Após a compactação, realizou-se uma escarificação com auxílio de enxada rotativa, deixando-se os $8 \mathrm{~cm}$ superficiais de solo revolvidos para dar condições iniciais de germinação e emergência. As diferentes compactações foram quantificadas pelas amostras indeformadas de solo e expressas em termos de densidade do solo $\left(\mathrm{g} \cdot \mathrm{cm}^{-3}\right)$.

A cultivar Carioca possui hábito de crescimento do tipo III (indeterminado prostrado), ciclo normal e resistência ao mosaico-comum. A 'Pérola' possui hábito II/III (semi-ereto a prostrado), ciclo normal e resistência ao mosaico-comum, ferrugem e mancha-angular (EMBRAPA, 1998).

A linhagem ESAL 550 da UFLA possui grão tipo jalo, hábito de crescimento III (semiprostrado), guias longos, semiprecoce e resistência à mancha-angular. A CI-128 da UFLA possui grão tipo carioca, hábito de crescimento indeterminado-III (prostrado), ciclo normal, resistência à antracnose e tolerância à mancha angular (Marinho, 1999).

Adotou-se espaçamento de $0,50 \mathrm{~m}$ entre linhas e densidade de semeadura de 16 sementes por metro. As parcelas foram constituídas de 5 linhas de 5 metros. A adubação de base foi equivalente a $500 \mathrm{~kg} . \mathrm{ha}^{-1}$ do fertilizante formulado 4-14-8, sendo a cobertura nitrogenada realizada aos 25 dias após a emergência (DAE) no primeiro experimento e aos 23 DAE no segundo, com $30 \mathrm{~kg} \cdot \mathrm{ha}^{-1}$ de $\mathrm{N}$, fonte sulfato de amônio.

Os experimentos foram mantidos livres da competição por plantas invasoras pela aplicação da mistura herbicida pós-emergente fomesafen $(1,0$ 1.ha $\left.{ }^{1}\right)+$ fluazifop-butil $\left(1,01 . \mathrm{ha}^{-1}\right)$, aos 15 e 23 DAE para o primeiro e segundo experimentos, respectivamente.

Em cada parcela, foram colhidas na fase de maturação fisiológica as três linhas centrais, retirando-se $0,50 \mathrm{~m}$ das extremidades (área útil de $12 \mathrm{~m}^{2}$ ). Foram avaliados os estandes inicial e final, bem como o rendimento de grãos e seus componentes (número de vagens por planta, número de grãos por vagem e massa de 100 grãos). Os estandes foram obtidos por contagem direta das plantas totais (com ou sem vagens), e o rendimento, pela trilha das plantas da área útil da parcela. O número de vagens por planta foi determinado por amostragem de 10 (dez) plantas por parcela, incluindo a contagem de vagens chochas, ou seja, sem grãos. O número de grãos por vagem foi obtido em amostra de 20 vagens.

Todos os dados foram submetidos à análise de variância individual por ensaio e conjunta, sendo os efeitos de cultivares estudados pela comparação de médias pelo teste de Tukey. Os efeitos de compactação do solo foram avaliados pela análise de regressão (Gomes, 1990).

\section{RESULTADOS E DISCUSSÃO}

Pela análise de variância conjunta, verificou-se que os estandes, o número de grãos por vagem e a massa de 100 grãos foram estimados com boa precisão, demonstrada pelos valores dos coeficientes de variação (CV\%) apresentados na Tabela 2, na qual também podem ser observados os valores médios das características nas duas safras. A precisão da estimativa do rendimento de grãos e do seu principal componente, número de vagens por planta, foi baixa.

Pela mesma análise constatou-se ainda que foi significativa a interação Safra x Densidade x Cultivar em relação aos estandes inicial e final, evidenciando que o comportamento do estande foi diferenciado em relação às safras e ao aumento da compactação do solo. Na Figura 1 apenas a cv. Pérola mostrou-se significativamente influenciada pelo aumento da densidade do solo em ambos os ensaios, e a cv. Carioca no ensaio da seca, com redução linear do estande inicial com o aumento da densidade do solo.

Na Figura 2, observa-se que o estande final foi influenciado na safra da seca somente pela cv. Carioca, e a ocorrência de fungos de solo contribuiu para a baixa população de plantas, e provavelmente não permitiu a detecção de efeito dos diferentes graus de compactação nas outras cultivares. A ocorrência de fungos de solo, constatada na safra da seca, teria sido conseqüência não só da própria compactação imposta na safra das águas, que criou um ambiente menos aerado e favorável ao desenvolvimento dos fungos, o que ocorre em maior freqüência em solos mais argilosos (Andrade, 1998), mas também da semeadura sucessiva do feijão na mesma área, aumentando a população de fungos pré-existentes. $\mathrm{Na}$ safra das águas, entretanto, apenas a linhagem CI128 não reduziu o estande final com o incremento da compactação. 
TABELA 1 - Resultados de análises química e granulométrica de amostras (em diferentes profundidades) do solo utilizado. UFLA, Lavras-MG, 1998/99(1).

\begin{tabular}{|c|c|c|c|}
\hline Atributos & Unidade & $0-20 \mathrm{~cm}$ & $20-40 \mathrm{~cm}$ \\
\hline $\mathrm{Al}$ & $\left(\mathrm{cmolc} \cdot \mathrm{dm}^{-3}\right)$ & $0,0 \mathrm{~B}$ & $0,0 \mathrm{~B}$ \\
\hline $\mathrm{Ca}$ & $\left(\mathrm{cmolc} \cdot \mathrm{dm}^{-3}\right)$ & $2,0 \mathrm{M}$ & $1,3 \mathrm{~B}$ \\
\hline $\mathrm{Mg}$ & $\left(\mathrm{cmolc} \cdot \mathrm{dm}^{-3}\right)$ & $0,2 \mathrm{~B}$ & $1,2 \mathrm{~A}$ \\
\hline $\mathrm{K}$ & $\left(\mathrm{mg} \cdot \mathrm{dm}^{-3}\right)$ & $86,0 \mathrm{~A}$ & $41,0 \mathrm{~B}$ \\
\hline $\mathrm{P}$ & $\left(\mathrm{mg} \cdot \mathrm{dm}^{-3}\right)$ & $7,0 \mathrm{M}$ & $1,0 \mathrm{~B}$ \\
\hline pH em água & $(1: 2,5)$ & 5,5 acidez média & 5,3 acidez média \\
\hline $\mathrm{H}+\mathrm{Al}$ & $\left(\mathrm{cmolc} \cdot \mathrm{dm}^{-3}\right)$ & $2,3 \mathrm{~B}$ & $2,1 \mathrm{~B}$ \\
\hline S.B. & $\left(\mathrm{cmolc} \cdot \mathrm{dm}^{-3}\right)$ & $2,4 \mathrm{M}$ & $2,6 \mathrm{M}$ \\
\hline $\mathrm{t}$ & $\left(\mathrm{cmolc} \cdot \mathrm{dm}^{-3}\right)$ & $2,4 \mathrm{~B}$ & $2,6 \mathrm{M}$ \\
\hline $\mathrm{T}$ & $\left(\mathrm{cmolc} \cdot \mathrm{dm}^{-3}\right)$ & $4,7 \mathrm{M}$ & $4,7 \mathrm{M}$ \\
\hline $\mathrm{m}$ & $(\%)$ & $0,0 \mathrm{~B}$ & $0,0 \mathrm{~B}$ \\
\hline V & $(\%)$ & $51,1 \mathrm{M}$ & $55,3 \mathrm{M}$ \\
\hline $\mathrm{S}-\mathrm{SO} 4$ & $\left(\mathrm{mg} \cdot \mathrm{dm}^{-3}\right)$ & 45,50 & 66,90 \\
\hline $\mathrm{B}$ & $\left(\mathrm{mg} \cdot \mathrm{dm}^{-3}\right)$ & 0,32 & 0,32 \\
\hline $\mathrm{Cu}$ & $\left(\mathrm{mg} \cdot \mathrm{dm}^{-3}\right)$ & 2,6 & 1,8 \\
\hline $\mathrm{Zn}$ & $\left(\mathrm{mg} \cdot \mathrm{dm}^{-3}\right)$ & 9,3 & 5,1 \\
\hline $\mathrm{Mn}$ & $\left(\mathrm{mg} \cdot \mathrm{dm}^{-3}\right)$ & 5,4 & 3,5 \\
\hline $\mathrm{Fe}$ & $\left(\mathrm{mg} \cdot \mathrm{dm}^{-3}\right)$ & 29,6 & 15,2 \\
\hline $\mathrm{C}$ & dag. $\mathrm{kg}^{-1}$ & 1,37 & 0,88 \\
\hline M.O. & dag. $\mathrm{kg}^{-1}$ & $2,36 \mathrm{M}$ & $1,52 \mathrm{~B}$ \\
\hline Argila & $(\%)$ & 70,0 & 70,0 \\
\hline Areia & $(\%)$ & 17,0 & 17,0 \\
\hline Silte & $(\%)$ & 13,0 & 13,0 \\
\hline
\end{tabular}

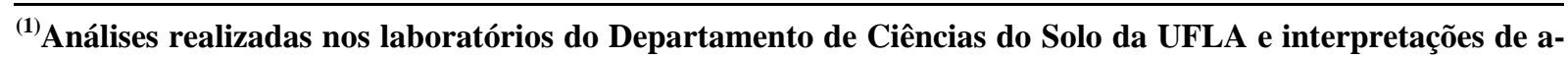
cordo com a Comissão de Fertilidade do Solo do Estado de Minas Gerais (1989). A , M , B = alto , médio ou baixo teor, respectivamente. 
TABELA 2 - Valores médios de safras, densidades do solo $\left(\mathrm{g} . \mathrm{cm}^{-3}\right)$, genótipos e coeficientes de variação em função dos estandes inicial e final, rendimento de grãos e seus componentes dos ensaios de duas safras. UFLA, LavrasMG, 1998/99.

\begin{tabular}{|c|c|c|c|c|c|c|}
\hline Fatores & $\begin{array}{c}\text { Estande inicial } \\
\left(\text { plantas.m }^{-1}\right)\end{array}$ & $\begin{array}{c}\text { Estande Final } \\
\left(\text { plantas.m }^{-1}\right)\end{array}$ & $\begin{array}{c}\text { Vagens por } \\
\text { planta }^{(1)}\end{array}$ & $\begin{array}{c}\text { Grãos por } \\
\text { vagem }\end{array}$ & $\begin{array}{l}\text { Massa de } 100 \\
\text { grãos (g) }\end{array}$ & $\begin{array}{c}\text { Rendimento } \\
\left(\text { kg.ha }^{-1}\right)\end{array}$ \\
\hline \multicolumn{7}{|l|}{ Safras } \\
\hline Águas & 14 & 13 & $4,0 \mathrm{~b}$ & 4,06 & 21,88 & 512 \\
\hline Seca & 9 & 7 & $6,2 \mathrm{a}$ & 4,90 & 22,94 & 566 \\
\hline \multicolumn{7}{|c|}{$\begin{array}{l}\text { Densidade aparente } \\
\left({\left.\mathrm{g} . \mathrm{cm}^{-3}\right)}^{-3}\right.\end{array}$} \\
\hline 1,08 & 12 & 11 & 5,8 & 4,7 & 23,14 & 819 \\
\hline 1,24 & 11 & 10 & 6,4 & 4,8 & 22,79 & 772 \\
\hline 1,36 & 11 & 9 & 5,2 & 4,8 & 22,44 & 434 \\
\hline 1,39 & 11 & 9 & 4,5 & 4,5 & 22,33 & 427 \\
\hline 1,41 & 11 & 9 & 4,3 & 4,4 & 21,71 & 392 \\
\hline 1,50 & 11 & 9 & 4,3 & 4,3 & 22,04 & 391 \\
\hline \multicolumn{7}{|l|}{ Genótipos } \\
\hline Pérola & 11 & 10 & $5,3 \mathrm{a}$ & 4,6 & 19,85 & 544 \\
\hline ESAL 550 & 11 & 9 & $3,8 \mathrm{~b}$ & 3,2 & 30,56 & 375 \\
\hline CI-128 & 11 & 10 & $5,5 \mathrm{a}$ & 4,9 & 21,65 & 729 \\
\hline Carioca & 12 & 10 & $5,7 \mathrm{a}$ & 5,2 & 17,58 & 508 \\
\hline Média & 11 & 10 & 5,1 & 4,5 & 22,41 & 539 \\
\hline $\mathrm{CV}(\%)$ & 7,05 & 10,95 & 29,55 & 14,85 & 10,26 & 31,75 \\
\hline
\end{tabular}

${ }^{(1)}$ Nas colunas, médias seguidas por letras iguais, não diferem entre si pelo teste de Tukey (5\%).

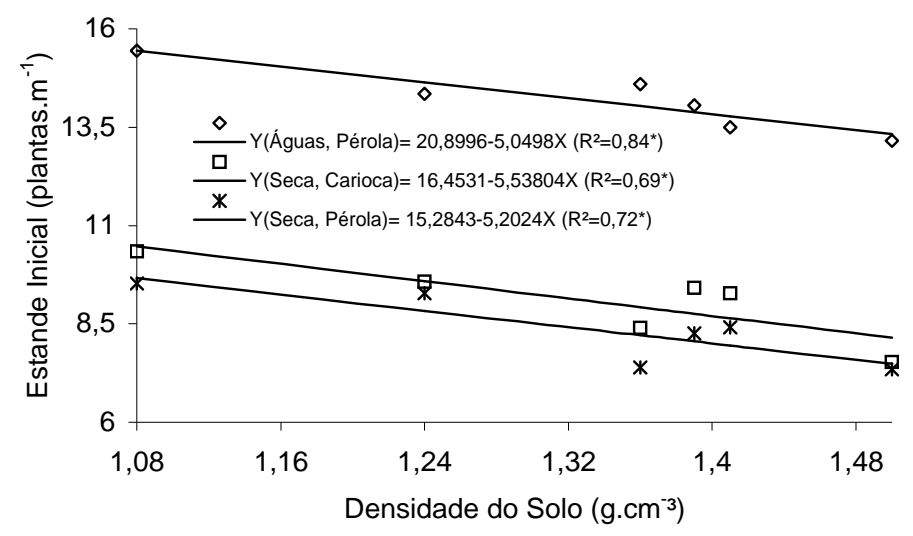

FIGURA 1 - Equação de regressão entre o estande inicial de dois genótipos de feijoeiro em duas safras e graus de compactação do solo. UFLA, Lavras-MG, 1998/99. 


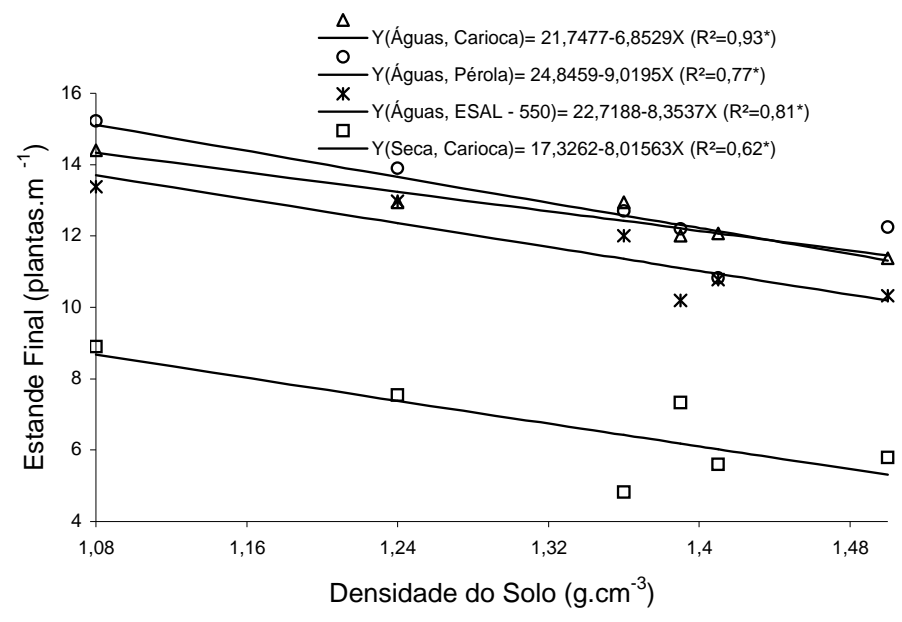

FIGURA 2 - Equação de regressão entre o estande final de três genótipos de feijoeiro em duas safras e graus de compactação do solo. UFLA, Lavras-MG, 1998/99.

Os casos em que os estandes inicial e final reduziram-se linearmente com o incremento da densidade do solo (Figuras 1 e 2) significaram que os processos de germinação e emergência foram influenciados pelo aumento da compactação. Adicionalmente, a redução do desenvolvimento radicular devido à compactação, relatada por alguns autores (Borges et al., 1988; Moraes, 1988; Corrêa et al., 1999), pode ter contribuído para menor desenvolvimento e sobrevivência das plantas.

Apesar da baixa precisão com que foi estimado o número de vagens por planta, a análise conjunta mostrou que safras e genótipos influenciaram essa variável (Tabela 2). Essa baixa precisão pode ser um indicativo da necessidade de se modificar a forma de amostragem e/ou aumentar o tamanho da amostra. O número de grãos por vagem, a massa de 100 grãos e o rendimento foram afetados pela interação safra $\mathrm{x}$ genótipo (Tabela 3). Pelos baixos valores obtidos para o rendimento de grãos, sugere-se que os resultados aqui obtidos sejam analisados com cautela e não sejam extrapolados para situações de altas produtividades, quando os resultados poderiam ser diferentes.

A linhagem ESAL 550 mostrou-se significativamente inferior aos demais genótipos em relação às variáveis número de grãos por vagem e número de vagens por planta (Tabelas 2 e 3), porém foi a que apresentou maior massa de 100 grãos, pelo fato de tratar-se de material do grupo "Manteigão" (Tabela 3). No ensaio das águas, a linhagem ESAL 550 foi inferior aos demais genótipos quanto ao rendimento de grãos; entretanto, no da 'seca', não diferiu das cultivares Carioca e Pérola. A linhagem CI-128 teve o rendimento de grãos superior aos demais genótipos no experimento da seca, mas não diferiu das cultivares Carioca e Pérola no experimento das águas, apesar de ter obtido o maior rendimento médio de grãos (Tabela 3).

A análise de variância conjunta revelou que embora a densidade do solo não tenha influenciado significativamente nos componentes do rendimento, o seu efeito sobre o rendimento de grãos foi altamente significativo.

O rendimento de grãos registrou drástica queda linear em razão do aumento da compactação do solo (Figura 3), certamente, por causa da menor população final de plantas (Figura 2) e da maior resistência do solo ao desenvolvimento radicular das plantas. Entretanto, pode ser verificado que houve tendência de redução dos três componentes do rendimento com o incremento da densidade do solo (Tabela 2); essa redução, ainda que não significativa, pode ter intensificado a redução do rendimento de grãos.

Observa-se na Figura 3 que, de acordo com o modelo ajustado aos dados, ao se aumentar a densidade de 1,08 para 1,50 g.cm ${ }^{-3}$ (espaço experimental estudado), o rendimento de grãos cairia de $851 \mathrm{~kg} \cdot \mathrm{ha}^{-1}$ para $327 \mathrm{~kg} \cdot \mathrm{ha}^{-1}$, correspondendo a uma redução de cerca de $62 \%$. Esses resultados confirmam os obtidos por Primavesi (1983) e são coerentes com aqueles obtido em outras culturas por Borges et al. (1988), Moraes (1988), Alvarenga (1993) e Corrêa et al. (1999). 
TABELA 3 - Valores médios dos componentes de produção, em função de genótipos. UFLA, Lavras-MG, $1998 / 99^{(1)}$.

\begin{tabular}{|c|c|c|c|c|c|c|}
\hline \multirow{3}{*}{ Genótipos } & \multicolumn{2}{|c|}{ Grãos/vagem } & \multicolumn{2}{|c|}{ Massa de 100 grãos } & \multicolumn{2}{|c|}{ Rendimento (kg.ha $\left.{ }^{-1}\right)$} \\
\hline & \multicolumn{2}{|c|}{ Safra } & \multicolumn{2}{|c|}{ Safra } & \multicolumn{2}{|c|}{ Safra } \\
\hline & Águas & Seca & Águas & Seca & Águas & Seca \\
\hline Carioca & $5,0 \mathrm{a}$ & $5,5 \mathrm{a}$ & $17,70 \mathrm{c}$ & $17,45 \mathrm{~d}$ & $564 \mathrm{a}$ & $452 \mathrm{~b}$ \\
\hline Pérola & $4,3 \mathrm{~b}$ & $5,0 \mathrm{~b}$ & $20,13 \mathrm{~b}$ & $19,57 \mathrm{c}$ & $552 \mathrm{a}$ & $536 \mathrm{~b}$ \\
\hline ESAL 550 & $2,5 \mathrm{c}$ & $3,9 \mathrm{c}$ & $28,33 \mathrm{a}$ & $32,78 \mathrm{a}$ & $260 \mathrm{~b}$ & $491 \mathrm{~b}$ \\
\hline CI-128 & $4,5 \mathrm{ab}$ & $5,3 \mathrm{ab}$ & $21,35 \mathrm{~b}$ & $21,95 \mathrm{~b}$ & $674 \mathrm{a}$ & $785 \mathrm{a}$ \\
\hline Média & 4,1 & 4,9 & 21,88 & 22,94 & 513 & 566 \\
\hline
\end{tabular}

(1)Médias seguidas por letras diferentes na colunas diferem entre si pelo teste de Tukey ao nível de $5 \%$ de probabilidade.

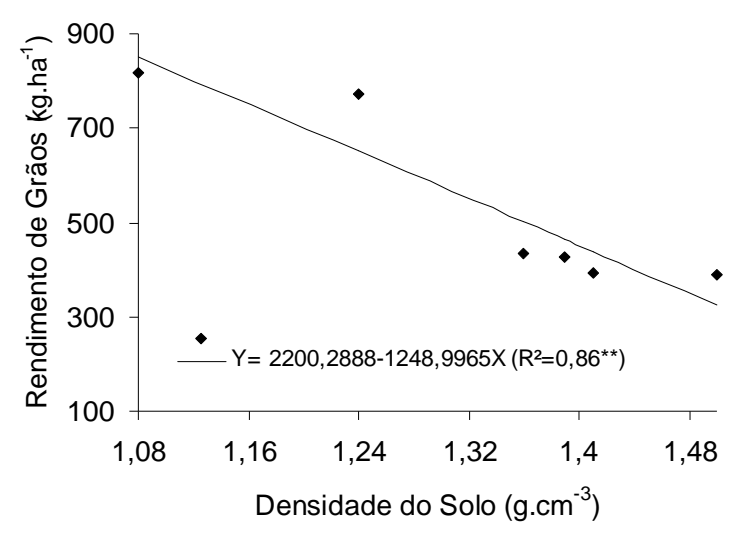

FIGURA 3 - Equaçao de regressao entre o rendımento de graos de quatro genotıpos de teijoeiro e graus de compactação do solo. UFLA, Lavras-MG, 1998/99.

\section{CONCLUSÕES}

a) O aumento do grau de compactação do solo reduziu linearmente o número de plantas, independente de safras e genótipos.

b) $\mathrm{O}$ efeito dos graus crescentes de compactação sobre o rendimento de grãos também foi linear e mais consistente, independente de safras e genótipos.

c) A linhagem CI-128 foi a mais produtiva na safra da seca e situou-se entre as melhores na safra das águas.

\section{REFERÊNCIAS BIBLIOGRÁFICAS}

ALVARENGA, C. R. Potencialidades de adubos verdes para conservação e recuperação de solos. 1993.
112 p. Tese (Doutorado) - Universidade Federal de Viçosa, Viçosa.

ANDRADE, M. J. B. Clima e Solo. In: VIEIRA, C.; PAULA JÚNIOR, T. J.; BORÉM, A. Feijão: aspectos gerais e cultura no Estado de Minas. Viçosa: UFV, 1998. p. 83-97

BORGES, E. N.; NOVAIS, R. F.; REGAZZI, A. J.; FERNANDES, B.; BARROS, N. F. Resposta de variedades de soja à compactação de camadas de solo. Revista Ceres, Viçosa, v. 35, p. 553-68, 1988.

CAMARGO, O. A.; ALLEONI, L. R. F. Compactação do solo e o desenvolvimento das plantas. Piracicaba: [s.n.], 1997. $132 \mathrm{p}$. 
CAUDLE, N. Physical constraints to root growth in savanna Oxisols. North Carolina: North Carolina State University, 1991. 28 p. (Tropical Soils Bulletin, 91-01).

COMISSÃO DE FERTILIDADE DO SOLO DO ESTADO DE MINAS GERAIS. Recomendações para o uso de corretivos e fertilizantes em Minas Gerais: $4^{\mathrm{a}}$ aproximação. Lavras, 1989. 176 p.

CORRÊA, J. B. D.; ANDRADE, L. A. B.; DIAS JUNIOR, M. S.; ALVES, V. G. Efeitos da compactação de três tipos de solos no rendimento de matéria seca de duas variedades de cana-de-açúcar, em condições de casa de vegetação. STAB, Piracicaba, v. 18, p. 32-34, 1999.

DEXTER, A. R. Model experiments on the behavior of roots at the interface between a tilled seed-bed and a compacted sub-soil. I. Effects of seed bed aggregate size and sub-soil strength on wheat roots. Plant Soil, Dordrecht, v. 95, p. 123-133, 1986.

EMPRESA BRASILEIRA DE PESQUISA AGROPECUÁRIA. Centro Nacional de Pesquisa Arroz e Feijão. Informativo anual das comissões técnicas regionais de feijão: cultivares de feijão recomendadas para plantio no ano agrícola 1998/99. Goiânia: EMBRAPACNPAF, 1998. 29 p.

GERARD, C. J.; SEXTON, P.; SHAW, G. Physical factors influencing soil strength and root growth. Agronomy Journal, Madison, v. 74, p. 875-879, 1982.

GOMES, F. P. Curso de Estatística Experimental. Piracicaba: Escola Superior de Agricultura "Luiz de Queiroz", 1990. 460 p.

LINDEMANN, W. C.; HAM, G. E.; RANDALL, G. W. Soil compaction effect on soybean nodulation, $\mathrm{N}_{2}$
$\left(\mathrm{C}_{2} \mathrm{H}_{4}\right)$ fixation and seed yield. Agronomy Journal, Madison, v. 74, p. 307-11, 1982.

LOWRY, F. E.; TAYLOR, H. M.; HUCK, M. G. Growth rate and yield od cotton as influenced by depth and bulk density of soil pans. Soil Society of America Proceeding, [S.1.], v. 34, n. 2, p. 306-309, 1970.

MARINHO, J. T. S. Comportamento de linhagens de feijoeiro em relação ao herbicida fomesafen. 1999. 64 p. Dissertação (Mestrado) - Universidade Federal de Lavras, Lavras.

MORAES, M. H. Efeitos de compactação em algumas proprieddes físicas do solo e no desenvolvimento do sistema radicular de plantas de soja (Glycine max (L.) Merrill). 1988. 105 p. Dissertação (Mestrado) Escola Superior de Agricultura "Luiz de Queiroz", Piracicaba.

MOURA FILHO, W.; BUOL, S. W. Studies of Latossol Roxo (Eutrustox) em Brazil. Experientiae, Viçosa, v. 13, p. 201-34, 1972.

PIZAIA, A. Desenvolvimento de conco cultivares de milho (Zea mays L.), em solo compactado, submetido a dois sistemas de cultivo. 1996. 79 p. Dissertação (Mestrado) - Universidade do Estado de São Paulo, Jaboticabal.

PRIMAVESI, O. Nutrição mineral de feijoeiro (Phaseolus vulgaris. L.), em dois solos sujeitos à compactação. 1983. 142 p. Dissertação) - Escola Superior de Agricultura "Luiz de Queiroz", Piracicaba.

SOANE, B. D. The effects of traffic and implements on soil compaction. Journal Prof. International Agric. Engng., [S.1.] v. 25, p. 115-26, 1970. 